ORIGINAL ARTICLE

\title{
Short term effects of particulate matter on cause specific mortality: effects of lags and modification by city characteristics
}

\author{
A Zeka, A Zanobetti, J Schwartz
}

Occup Environ Med 2005;62:718-725. doi: 10.1136/oem.2004.017012

See end of article for authors' affiliations

\section{Correspondence to:} Dr A Zeka, Exposure, Epidemiology, and Risk Program, Department of Environmental Health, Harvard School of Public Health, 401 Park Drive, Suite $415 \mathrm{~W}, \mathrm{PO}$ Box 15677, Boston, MA 02215, USA; azeka@ hsph.harvard.edu

Accepted 18 March 2005

\begin{abstract}
Background: Consistent evidence has shown increased all-cause mortality, and mortality from broad categories of causes associated with airborne particles. Less is known about associations with specific causes of death, and modifiers of those associations.

Aims: To examine these questions in 20 US cities, between 1989 and 2000.

Methods: Mortality files were obtained from the National Center for Health Statistics. Air pollution data were obtained from the Environmental Protection Agency website. The associations between daily concentrations of particulate matter of aero-diameter $\leqslant 10 \mu \mathrm{m}\left(\mathrm{PM}_{10}\right)$ and daily mortality from all-cause and selected causes of death, were examined using a case-crossover design. Temporal effects of $\mathrm{PM}_{10}$ were examined using lag models, in first stage regressions. City specific modifiers of these associations were examined in second stage regressions.

Results: All-cause mortality increased with $\mathrm{PM}_{10}$ exposures occurring both one and two days prior the event. Deaths from heart disease were primarily associated with $\mathrm{PM}_{10}$ on the two days before, while respiratory deaths were associated with $\mathrm{PM}_{10}$ exposure on all three days. Analyses using only one lag underestimated the effects for all-cause, heart, and respiratory deaths. Several city characteristics modified the effects of $\mathrm{PM}_{10}$ on daily mortality. Important findings were seen for population density, percentage of primary $\mathrm{PM}_{10}$ from traffic, variance of summer temperature, and mean of winter temperature.

Conclusions: There was overall evidence of increased daily mortality from increased concentrations of $\mathrm{PM}_{10}$ that persisted across several days, and matching for temperature did not affect these associations. Heterogeneity in the city specific $\mathrm{PM}_{10}$ effects could be explained by differences in certain city characteristics.
\end{abstract}

$S$ hort term increases in concentrations of airborne particles, complex mixtures of solid and liquid droplets, have been associated with immediate increases in mortality events. ${ }^{1-4}$ The largest study of air pollution, the National Morbidity and Mortality Study (NMMAPS), examined this association in all the cities in the United States. ${ }^{5}$ The important evidence coming from this study confirmed previous findings on the positive association between particulate matter of aero-diameter equal or less then $10 \mu \mathrm{m}\left(\mathrm{PM}_{10}\right)$ and daily deaths, and proved that such relation was little changed when controlling for any gaseous pollutant. They also confirmed that none of the gaseous pollutants had an independent effect on the daily mortality. However, because the NMMAPS included cities that only monitored $\mathrm{PM}_{10}$ one day in six, it could only examine lags one day at a time, thus it could not address whether the mortality association persisted across several days.

Most of the evidence for the positive effects of $\mathrm{PM}_{10}$ has been generally shown in association with all-cause mortality, ${ }^{6-8}$ or mortality from all respiratory and/or cardiovascular disease. $^{9-12}$ Such a broad definition of cause of death can possibly underestimate the magnitude of the association that one would observe had a more specific classification of diseases been used. Only a few studies to date have examined the acute effects of particulate matter and cause specific daily mortality, ${ }^{13-17}$ and fewer were multi-city studies.

Differing results with the more specific definition of mortality causes may aid our understanding of the possible mechanisms that induce the $\mathrm{PM}_{10}$ related events. Particles are thought to be involved in complex inflammatory responses in animals and humans, which could lead to cardiovascular and/or pulmonary effects, and possibly to cardiovascular and/or pulmonary events. ${ }^{18-24}$ Experimental studies have shown that exposures to concentrated air particles induce pulmonary inflammatory response, such as alveolar cytokine release, responsible for bronchospasm, and reduction of pulmonary function. ${ }^{25-27}$ The mechanisms leading to cardiovascular effects have been suggested to be a result of increasing blood clotting factors such as increased serum levels of fibrinogen, ${ }^{25}{ }^{26}$ increased inflammatory factors like C-reactive protein, ${ }^{22}$ or cardiotoxicity by mechanisms such as the increase of plaque formation and decrease of plaque stability, ${ }^{28}$ vasoconstriction and temporary coronary occlusion, ${ }^{29}{ }^{30}$ and ischaemia. ${ }^{28}$ Increased reactive oxygen species in the lung and heart have been produced by exposure to concentrated air particles as well. ${ }^{31}$ Epidemiological studies have suggested similar mechanisms. Increased concentrations of particulate matter have been associated with plasma viscosity ${ }^{18}$ and fibrinogen ${ }^{32}$ which are suspected risk factors for cardiovascular disease. Results for C-reactive protein concentrations have been mixed. ${ }^{22} 3334$

In the present study we examined the acute effects of particulate matter on all-cause and cause specific daily mortality for a list of diseases. For this, we obtained detailed mortality files for a 12 year period between 1989 and 2000.

Abbreviations: AT, apparent temperature; COPD, chronic obstructive pulmonary disease; $\mathrm{HF}$, heart failure; ICD, International Classification of Diseases; IHD, ischaemic heart disease; MI, myocardial infarction;

NMMAPS, National Morbidity and Mortality Air Pollution Study; $\mathrm{NO}_{2}$, nitrogen dioxide; $\mathrm{PM}_{10}$, particulate matter of aero-diameter equal or less than $10 \mu \mathrm{m}$ 
We used publicly available sources to obtain air pollution data and weather data for the same time period. A casecrossover design analysis was used to evaluate the acute effects of daily $\mathrm{PM}_{10}$ concentrations on mortality. Short term effects of particulate matter on daily mortality were examined using lag models. Several studies have examined factors that may explain heterogeneity in the effects of $\mathrm{PM}_{10}$ by location (city). ${ }^{85} 36$ We examined the potential for effect modification of the $\mathrm{PM}_{10}$-daily mortality estimates by city characteristics, specifically the prevalence of central air conditioning, population density, standardised mortality rates, the proportion of elderly in each city, daily minimum apparent temperature in summer (mean and variance), daily maximum apparent temperature in winter (mean and variance), and percentage of primary $\mathrm{PM}_{10}$ from traffic sources.

\section{METHODS}

The study included a period of 12 years between 1 January 1989 and 31 December 2000. We selected 20 cities in the United States with sufficient mortality and daily air pollution data: Birmingham, Alabama; Boulder, Colorado; Canton, Ohio; Chicago, Illinois; Cincinnati, Ohio; Cleveland, Ohio; Colorado Springs, Colorado; Columbus, Ohio; Denver, Colorado; Detroit, Michigan; Honolulu, Hawaii; Minneapolis, Minnesota; Nashville, Tennessee; New Haven, Connecticut; Pittsburgh, Pennsylvania; Provo, Utah; Salt Lake City, Utah; Seattle, Washington; Terra Haute, Indiana; and Youngstown, Ohio.

\section{Daily mortality}

Mortality files were obtained from the National Center for Health Statistics (NCHS) for the period between 1989 and 2000. The mortality files provided information on the exact date of death, and the underlying cause of death. For this study we selected all-cause daily mortality excluding any deaths from accidental causes (ICD code, 10th revision V01Y98). Specific cause mortality case groups were derived from this previous group for the following underlying causes of death: heart disease (I01-I51), ischaemic heart disease (IHD) (I20-I25), myocardial infarction (MI) (I21, I22), dysrhythmias (I46-I49), heart failure (HF) (I50), stroke (I60-I69), respiratory disease (J00-J99), pneumonia (J12-J18), and chronic obstructive pulmonary disease (COPD) (J40-J44, J47).

\section{Air pollution}

Data for $\mathrm{PM}_{10}$ were obtained from the United States Environmental Protection Agency Aerometric Information Retrieval System (US EPA AIRS) for the same period of years. ${ }^{37}$ US EPA AIRS retrieves data from multiple monitors in each county for daily and hourly average measurements. The sampling method for hourly data uses monitors which are susceptible to a greater loss of semi-volatile particles from traffic, than the integrated 24 hour (daily) monitors. The hourly monitors heat the sample to $50^{\circ} \mathrm{C}$ to remove water from the mass, and in doing so it volatilises the semi-volatile PM components. Even more complicated is the fact that the amount of semi-volatile mass for a given sample in the hourly measurements will likely vary by location, season, and even time of day, thus requiring constant adjustments by a reference method. Therefore, the integrated method provided the highest quality data for our analysis. ${ }^{38} 39$

Air pollution data from multiple monitors in each city were used to estimate a common value for the city, using an averaging method based on an algorithm described previously by Schwartz. ${ }^{35}$ However, before applying this algorithm, we made sure that all monitors in one city represented general ambient exposures, and not rather a local source. For this, we calculated the correlation between city monitors. We obtained multiple correlation coefficients for each monitor (correlated with all other monitors in the city), from which we extracted the median values. Those monitors falling in the low 10th centile of the distribution of the median values, across all cities, were excluded from the analyses.

While we selected cities with daily $\mathrm{PM}_{10}$ monitoring, daily concentrations of $\mathrm{PM}_{10}$ were occasionally missing. Even small numbers of missing data can present a problem when examining multiple lags of exposure in a model. We used regression models to predict missing $\mathrm{PM}_{10}$ daily values using local meteorological data obtained from the United States Surface Airways and Airways Solar Radiation hourly data (NESDIS) (including extinction coefficient, ${ }^{40}$ a measure of light scattering by fine particles), and the $\mathrm{PM}_{10}$ concentration the day before and the day after. Prior to filling in the missing values, we made sure that we used only months missing less than $25 \%$ of the days, and $\mathrm{PM}_{10}$ daily values equal or less than $300 \mu \mathrm{g} / \mathrm{m}^{3}$.

\section{Statistical methods of analysis}

A case-crossover design was carried out to examine the association between daily mortality and $\mathrm{PM}_{10}$. The approach, first described by Maclure, ${ }^{41}$ is similar in concept to a casecontrol study, except that now cases and controls are the same subject, but in different times. A case is defined by the time of the event (day of the event in our case), and controls are chosen as the times (days) free of the event, selected to be close to the event day in time. Bateson and Schwartz showed that such matching can control even strong confounding by season and time trends. ${ }^{42}{ }^{43}$ We chose these control days by using a time stratified approach. ${ }^{44}$ This involves choosing control days to be all other days (or a sample of all other days) of a fixed time strata, typically the same month of the same year as the event. Using monthly strata has been shown to produce unbiased estimates of effect sizes and coverage probabilities even in the presence of strong seasonal confounding. ${ }^{45}$ Control days have different exposures from that of the case, since exposures change from day to day. As in a matched case-control study, conditional logistic regression is applied to the matched pairs to compare different characteristics between the case day (day of the event) and its control days (days free of the event), including exposure characteristics. Because of its design, the case-crossover approach controls for factors that change slowly over time, ${ }^{42}{ }^{43}$ or factors that are individual characteristics which may, in another case, be potential confounders. ${ }^{41}$ In our study, controls were selected within the month of the event, leaving two days between each control day to eliminate any serial correlation.

The statistical modelling involved two hierarchical stages. Effects of $\mathrm{PM}_{10}$ on daily mortality were first estimated through city specific models, in the first stage analyses. Risk of mortality was evaluated in association with $\mathrm{PM}_{10}$ exposure concentrations on the same day of the event (lag 0 ), one (lag 1 ), and two days (lag 2) prior the event. The models included one lag at a time (single lag models), or all three lags. The latter is described as a "distributed lag model" and is a way to estimate unbiased time trends of the exposure-response relation, by controlling for confounding in exposure effects in one lag by exposures in other lags. ${ }^{46}$ All models included "day of week" as indicator variables, and quadratic spline functions for apparent temperature (AT) on the same day and the day before death, to control for effect of weather, ${ }^{47}{ }^{48}$ in the form: $\mathrm{AT}_{\mathrm{ij}}+\mathrm{AT}_{\mathrm{ij}}{ }^{2}+\left(\mathrm{AT}_{\mathrm{ij}}-\text { city specific mean } \mathrm{AT}_{\mathrm{ij}}\right)_{+}{ }^{2}$, where i represents city, and $\mathrm{j}$ represents lag of AT. Given the humidity, AT is defined as the perceived body temperature, and was calculated as: $\mathrm{AT}=-2.653+\left(0.994^{*} \mathrm{Ta}\right)+$ 
Table 1 Characteristics* of the 20 cities in the United States included in the study of the association between $\mathrm{PM}_{10}$ and daily mortality, between 1989 and 2000

\begin{tabular}{|c|c|c|c|c|c|c|c|}
\hline City & $\begin{array}{l}\text { Population } \\
\text { density }\end{array}$ & $\begin{array}{l}\% \text { central } \\
\mathrm{AC} \ddagger\end{array}$ & $\begin{array}{l}\text { Minimum summer } \\
\text { AT (SD) ( } \mathrm{C} \text { ) }\end{array}$ & $\begin{array}{l}\text { Maximum winter } \\
\text { AT (SD) ( } \mathrm{C} \text { ) }\end{array}$ & $\begin{array}{l}\text { Mean } \mathrm{PM}_{10} \\
(\mathrm{SD})\left(\mu \mathrm{g} / \mathrm{m}^{3}\right)\end{array}$ & $\begin{array}{l}\% \text { of primary } \\
\mathrm{PM}_{10} \text { from } \\
\text { traffic } \$\end{array}$ & $\begin{array}{l}\text { Standardised } \\
\text { mortality rates }\end{array}$ \\
\hline Birmingham, Alabama & 422 & 70.2 & $29.3(3.3)$ & $6.7(5.8)$ & $31.9(18.0)$ & 1.5 & 0.0107 \\
\hline Boulder, Colorado & 393 & 6.3 & $20.1(3.3)$ & $-1.2(5.4)$ & $22.1(11.3)$ & 1.7 & 0.0066 \\
\hline Canton, Ohio & 656 & 30 & $22.5(4.6)$ & $-3.0(5.5)$ & $26.6(11.5)$ & 3.0 & 0.0098 \\
\hline Chicago, Illinois & 5684 & 43.2 & $23.6(5.3)$ & $-3.5(4.9)$ & 33.7 (16.4) & 5.0 & 0.0077 \\
\hline Cincinnati, Ohio & 2077 & 66.2 & $25.1(4.5)$ & $-0.5(6.0)$ & $31.4(13.9)$ & 2.8 & 0.0083 \\
\hline Cleveland, Ohio & 3044 & 39.3 & $23.2(4.8)$ & $-2.2(5.7)$ & $37.5(18.7)$ & 4.8 & 0.0064 \\
\hline Colorado Springs, Colorado & 243 & 13.4 & $18.3(3.6)$ & $-0.9(5.3)$ & $24.0(13.2)$ & 1.6 & 0.0086 \\
\hline Columbus, Ohio & 1980 & 63.7 & $24.6(4.7)$ & $-1.4(4.7)$ & $28.5(12.5)$ & 3.0 & 0.0127 \\
\hline Denver, Colorado & 3625 & 25.7 & $20.1(3.6)$ & $-0.9(5.6)$ & $28.5(12.8)$ & 3.0 & 0.0094 \\
\hline Detroit, Michigan & 3357 & 41 & $23.2(4.9)$ & $-3.1(4.4)$ & $32.1(17.7)$ & 7.5 & 0.0086 \\
\hline Honolulu, Hawaii & 1460 & - & $29.0(1.3)$ & $24.9(1.9)$ & $15.9(6.8)$ & 2.8 & 0.0079 \\
\hline Minneapolis, Minnesota & 2282 & 48.4 & $22.3(4.9)$ & $-6.6(4.5)$ & 24.7 (12.3) & 4.2 & 0.0096 \\
\hline Nashville, Tennessee & 1135 & 72.2 & $28.7(3.8)$ & $3.8(6.0)$ & $30.1(12.1)$ & 2.5 & 0.0112 \\
\hline New Haven, Connecticut & 1360 & 23.9 & $23.1(4.6)$ & $-2.0(4.2)$ & $25.4(14.4)$ & 5.6 & 0.0104 \\
\hline Pittsburgh, Pennsylvania & 1756 & 33.4 & $23.3(4.4)$ & $-1.5(5.3)$ & $30.2(18.5)$ & 5.0 & 0.0090 \\
\hline Provo, Utah & 185 & 26.9 & $22.4(4.3)$ & $-2.0(4.1)$ & $33.7(22.2)$ & 2.2 & 0.0098 \\
\hline Seattle, Washington & 817 & 6.2 & $17.0(3.6)$ & $3.1(3.5)$ & $26.4(14.7)$ & 2.8 & 0.0130 \\
\hline Salt Lake City, Utah & 1219 & 39.7 & $22.4(4.4)$ & $-2.1(4.1)$ & $35.0(20.8)$ & 3.0 & 0.0082 \\
\hline Terra Haute, Indiana & 262 & 71.6 & $24.8(4.4)$ & $-3.6(5.4)$ & $29.2(14.6)$ & 1.9 & 0.0075 \\
\hline Youngstown, Ohio & 390 & 22.8 & $22.1(4.7)$ & $-2.9(4.8)$ & $30.8(13.9)$ & 2.9 & 0.0077 \\
\hline
\end{tabular}

$A C$, air conditioning; $A T$, apparent temperature; $\mathrm{PM}_{10}$, particulate matter of aero-diameter equal or less than $10 \mu \mathrm{m} ; \mathrm{SD}$, standard deviation.

${ }^{*}$ All descriptive statistics for weather and $\mathrm{PM}_{10}$ concentrations were extracted from the available data between 1989 and 2000.

†United States Census 2000 data (count/mile ${ }^{2}$ ).

$\ddagger$ American Housing Survey (AHS), Unites States Census Bureau, between 1994 and 2000. Data for Honolulu, HI are missing due to no available data after 1983 from the AHS.

§Data obtained from the United States Environmental Protection Agency website: www.http://www.epa.gov/ttn/

- Age standardised mortality rates were computed using United States population as the standard population, retrieved from the 2000 Census Data.

$\left(0.0153^{*} \mathrm{Td}^{2}\right)$, where Ta is air temperature and $\mathrm{Td}$ is dew point temperature. ${ }^{49} 50$

Another way to control for effect of whether, is to match on AT. ${ }^{51}$ We carried out additional analyses, where control days were matched on AT (on the same day, rounded in ${ }^{\circ} \mathrm{C}$ ), month, and year as the event day. The models included additionally indicator variables for "day-of-week", and a quadratic spline function for AT one day before the event.

Estimates obtained from the distributed lag models were used to estimate the cumulative effects in each city, computed by summing the coefficients across all three days, that of the event, and two days before. ${ }^{46}$ The overall variance was computed as:

$$
\operatorname{Var}\left(\sum \hat{\beta}_{i j}\right)=\sum \operatorname{Var}\left(\hat{\beta}_{i j}\right)+\sum \operatorname{Cov}\left(\hat{\beta}_{i j}\right)
$$

where $\hat{\beta}_{i j}$ is the city-specific lag-specific slope, $i$ represents city, and $j=0,1,2$ defines lag.

In the second stage analyses, maximum likelihood metaregression models estimated summary effects for mortality causes and $\mathrm{PM}_{10}$ associations across the 20 cities, allowing

Table 2 Daily mortality in the 20 cities in the United States, between 1989 and 2000

\begin{tabular}{|c|c|c|c|c|c|}
\hline \multirow[b]{2}{*}{ City } & \multicolumn{2}{|l|}{ All-cause ${ }^{*}$} & \multirow[b]{2}{*}{$\begin{array}{l}\text { Respiratory } \\
\text { disease }\end{array}$} & \multirow[b]{2}{*}{$\begin{array}{l}\text { Heart } \\
\text { disease† }\end{array}$} & \multirow[b]{2}{*}{ Stroke† } \\
\hline & Total deaths & $\begin{array}{l}\text { Deaths/ } \\
100000 \ddagger\end{array}$ & & & \\
\hline Birmingham, Alabama & 41398 & 1401 & 9 & 32 & 8 \\
\hline Boulder, Colorado & 9551 & 441 & 12 & 31 & 8 \\
\hline Canton, Ohio & 34061 & 1055 & 11 & 35 & 7 \\
\hline Chicago, Illinois & 534793 & 921 & 9 & 36 & 6 \\
\hline Cincinnati, Ohio & 82455 & 1136 & 10 & 33 & 7 \\
\hline Cleveland, Ohio & 188434 & 1192 & 8 & 38 & 6 \\
\hline Colorado Springs, Colorado & 17518 & 508 & 14 & 28 & 9 \\
\hline Columbus, Ohio & 33472 & 886 & 8 & 34 & 6 \\
\hline Denver, Colorado & 41313 & 1049 & 13 & 29 & 7 \\
\hline Detroit, Michigan & 213352 & 1024 & 8 & 39 & 6 \\
\hline Honolulu, Hawaii & 17255 & 663 & 10 & 32 & 10 \\
\hline Minneapolis, Minnesota & 155078 & 1265 & 10 & 27 & 8 \\
\hline Nashville, Tennessee & 64187 & 1254 & 10 & 33 & 8 \\
\hline New Haven, Connecticut & 94502 & 1019 & 10 & 35 & 6 \\
\hline Pittsburgh, Pennsylvania & 169098 & 1387 & 9 & 37 & 7 \\
\hline Provo, Utah & 15289 & 392 & 11 & 31 & 9 \\
\hline Seattle, Washington & 101626 & 709 & 11 & 31 & 8 \\
\hline Salt Lake City, Utah & 54825 & 579 & 10 & 28 & 7 \\
\hline Terra Haute, Indiana & 5035 & 1352 & 9 & 37 & 8 \\
\hline Youngstown, Ohio & 23064 & 1122 & 8 & 38 & 8 \\
\hline
\end{tabular}

*Primary cause of death from injuries was excluded (see text for reference).

†Percentage of all-cause mortality.

$\ddagger$ Numbers represent average annual mortality per 100,000 . 
for heterogeneity in city specific response using a random effect model. ${ }^{52}$

\section{Effect modification}

We examined the potential for effect modification of the cumulative $\mathrm{PM}_{10}$-mortality estimates by city characteristics including the prevalence of central air conditioning, population density, standardised mortality rates, the proportion of elderly in each city (greater than 65,75 , or 85 years old), daily minimum apparent temperature (mean and variance) in summer (June, July, August), daily maximum apparent temperature (mean and variance) in winter (December, January, February), and percentage of primary $\mathrm{PM}_{10}$ from traffic sources. These factors were examined in the second stage random meta-regressions. ${ }^{8} 3536$

The estimates of $\mathrm{PM}_{10}$-mortality association reported in this paper refer to percentage increase in mortality per any $10 \mu \mathrm{g} / \mathrm{m}^{3}$ increment of $\mathrm{PM}_{10}$ concentration. SAS statistical software package was used for all data management, and statistical analyses of the first stage. S-plus was used to implement the Berkey method for random meta-regression analyses. $^{52}$

\section{RESULTS}

The 20 selected cities showed variability in the city-specific characteristics (table 1). In several cities, the higher population density corresponded well with higher percentage of primary $\mathrm{PM}_{10}$ from traffic sources, suggesting highly urbanised areas. Some cities had relatively high percentages of central air conditioning including Birmingham, Cincinnati, Columbus, Nashville, and Terra Haute, which was also consistent with higher summer AT. Overall mean concentration of $\mathrm{PM}_{10}$ varied by city and across time within city. Birmingham, Cleveland, Provo, and Salt Lake City had higher and more variable concentrations of daily $\mathrm{PM}_{10}$.

Average annual mortality events per 100000 were higher in Birmingham, Minneapolis, Nashville, Pittsburgh, and Terra Haute. Mortality from any respiratory disease was about $10 \%$ of all-cause mortality (table 2), and of these, 40 $50 \%$ were deaths from chronic obstructive pulmonary disease (COPD), and about 35\% were deaths from pneumonia. One third of all deaths were from heart disease, the majority of which were ischaemic heart disease (IHD) $(70 \%)$, and in small proportions heart failure (HF) (6\%), and dysrhythmias $(6 \%)$. Almost half of ischaemic heart disease mortality cases were diagnosed as acute myocardial infarction (MI). Mortality from stroke was about $7 \%$ of all-cause mortality (table 2). In total, we studied 1896306 deaths.

Single lag model results showed, in general, increased risk of mortality with concentrations of $\mathrm{PM}_{10}$ the day before and two days before of the event (lags 1 and 2) (table 3). Because of the potential bias due to confounding from exposures in other days, the results from the unconstrained distributed lag models presented more valid estimates of the distribution of the effects of $\mathrm{PM}_{10}$ over time (table 3). All-cause mortality increased with increasing concentrations of $\mathrm{PM}_{10}$ the day before and two days before the event, with effects essentially zero on the same day. When we examined broad categories of mortality causes, we saw different patterns. Respiratory mortality effects were distributed over all three lags. In contrast, cardiac deaths were associated with exposure the day before and two days before the death. The more specific causes had more mixed patterns, but the standard errors of the effect estimates for these rarer outcomes were large, limiting interpretation of the distributed lag pattern. Interesting to note was the strong positive association for mortality from heart failure with concentrations two days prior the event.
The cumulative increase for all-cause mortality due to $\mathrm{PM}_{10}$ concentrations across the three days was $0.45 \%$, which was about a quarter more than what was seen with the strongest single day lag. All respiratory mortality increased $0.87 \%$ across the three days. The largest impact of $\mathrm{PM}_{10}$ concentrations in these three days was on the deaths from pneumonia (1.24\%). Deaths from any heart disease showed a $0.50 \%$ increase. The cumulative increase for IHD over the three days was somewhat greater than for all heart disease mortality. Mortality from stroke showed a $0.46 \%$ relative increase, although imprecisely estimated.

Matching on AT resulted in less power, thus it was difficult to interpret the results for cause specific mortality. However, the effects on all-cause mortality did show a similar pattern with the results of models that had included AT as a covariate. Overall, the estimate for all-cause mortality was $0.52 \%$ ( $95 \%$ CI $0.31 \%$ to $0.72 \%$ ).

We found no great impact of city-level characteristics on the overall estimates of $\mathrm{PM}_{10}$-cause specific mortality, although power was weak for cause specific deaths. However, we observed differences in the $\mathrm{PM}_{10}$ effects for all-cause mortality for several of these characteristics (table 4). Percentage increase in daily mortality was higher for denser populated areas (90\% greater comparing locations with 3000 persons/mile ${ }^{2}$ to locations with 1000 persons/ mile $^{2}$ ), and higher for those cities with a higher fraction of primary $\mathrm{PM}_{10}$ from traffic (threefold comparing the estimate for the 75th centile with that of the 25th centile of the distribution). Higher variability in summer apparent temperature was associated with a greater impact of $\mathrm{PM}_{10}$ (about sixfold for the comparison of the interquartile range, 25 th to 75 th centile), as were lower winter temperatures (44\% increase comparing the 75th and 25th centiles of the distribution). These important findings are also illustrated in fig 1 . There was an indication that a greater proportion of the elderly in the city also modified the effect of $\mathrm{PM}_{10}$ on daily mortality (proportion of those older than 65 or 75 years, with the difference between the first and third quartiles being $56 \%$ and $51 \%$ respectively) (table 4 ).

\section{DISCUSSION}

In a large, multi-city study, we examined the effects of $\mathrm{PM}_{10}$ on daily mortality across three days: on the day of the event (death), and one and two days before, using a case-crossover design. We observed increased all-cause mortality for increasing concentrations of $\mathrm{PM}_{10}$ on the day before and two days before the event.

Some previous studies have been criticised for reporting the $\mathrm{PM}_{10}$ effects on mortality for the exposure lag showing the strongest association. It has been argued that this overestimates the effect of exposure. However, we found that considering the multi-day effects increased our estimates of the short term effects of $\mathrm{PM}_{10}$ on all-cause mortality by about one quarter, compared to even the strongest lag. This finding is important for risk assessment, suggesting that effect estimates from studies that used a single day rather than a distributed lag exposure, will be lower. The effect of $\mathrm{PM}_{10}$ on mortality from respiratory causes persisted in all three days. This was also true for pneumonia deaths, whereas deaths from COPD were predominantly associated with $\mathrm{PM}_{10}$ concentrations the two days before. Deaths from all heart disease showed association primarily with concentrations of $\mathrm{PM}_{10}$ the two days before (lags 1 and 2). However, mortality from myocardial infarction was only associated with concentrations on the same day. We found a larger, but imprecise association with heart failure deaths. Stroke daily deaths were mainly associated with the day before concentrations (lag 1), although imprecisely estimated. Because of insufficient power, we could not make stronger conclusions 


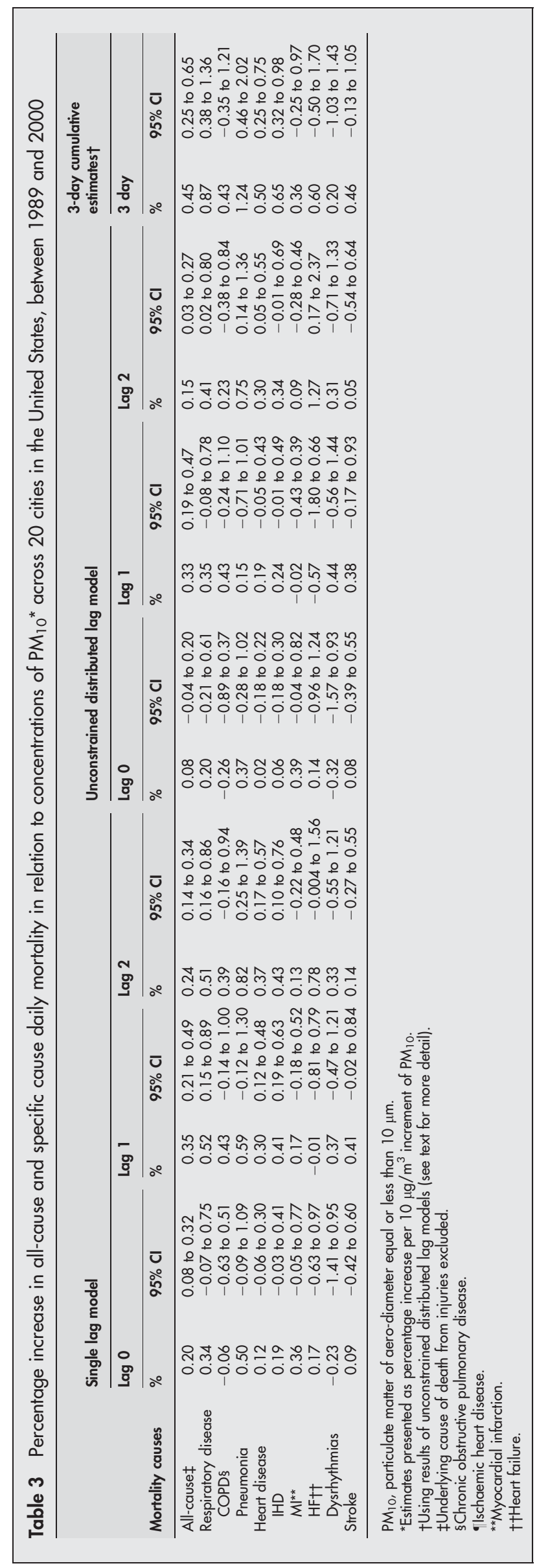

about most of the specific causes of death. However, it is important to note the doubling of the effect for respiratory mortality when compared to all-cause mortality. The effect was as large in an analysis of all-cause mortality- $\mathrm{PM}_{10}$ association, where we used an interaction term for all respiratory deaths $(0.72 \% ; 95 \%$ CI $0.28 \%$ to $1.16 \%)$.

The findings of the study add to the previous literature in several ways. It confirms in a large multi-city US study with extended follow up (to 2000) what has previously been reported in Europe. ${ }^{8}$ The effects of $\mathrm{PM}_{10}$ on daily deaths persisted over at least two days, and incorporating that persistence resulted in higher effect estimates. The other largest study in the United States that had looked at the $\mathrm{PM}_{10}$-mortality association, due to the monitoring limitation could not examine the question of persistent effects in the course of more than one day. ${ }^{5}$ The results of the present study corroborated previous results reported by Braga and colleagues $^{13}$ and Schwartz, ${ }^{46}$ which had used more limited data.

The persistent $\mathrm{PM}_{10}$ effects for respiratory mortality, and in particular pneumonia deaths supported epidemiological findings for an exacerbation of inflammation in immunocompromised subjects. ${ }^{53}$ Zelikoff and colleagues suggested that $\mathrm{PM}_{10}$ may act as an immunosuppressive agent which can disrupt normal pulmonary antimicrobial defence mechanisms, and illustrated this in animal models. ${ }^{54}$ They showed that even single exposures to ambient particulate matter are able to compromise normal recovery mechanisms.

The findings for myocardial infarction were consistent with the suggested mechanisms for exposure related triggering of coronary events within 24 hours. ${ }^{55-57}$ We confirmed the reports of Hoek and colleagues ${ }^{58}$ and Goldberg and colleagues $^{59}$ that heart failure appears a particularly sensitive outcome. However, those previous studies could only investigate single locations. We also provided suggestive evidence that mortality from stroke was associated with $\mathrm{PM}_{10}$ in the United States. This has been previously only reported in Asian populations. ${ }^{14-17}$

We have also confirmed the findings reported in a more limited study by Schwartz, ${ }^{51}$ that choosing control days matched to the same temperature as the event days, did not change the $\mathrm{PM}_{10}$ effects. This indicates that the observed $\mathrm{PM}_{10}$-mortality associations were unlikely to be due to temperature confounding.

We considered the hypothesis that heterogeneity in the city $\mathrm{PM}_{10}$ effects could be due to certain city sociodemographic, physical, and environmental characteristics. The study of Janssen et al had reported differing of the $\mathrm{PM}_{10}$ effects on cardiovascular hospital admissions due to differences in the proportion of central air conditioning in each city. ${ }^{36}$ They also observed important difference by source of primary $\mathrm{PM}_{10}$, with traffic sources showing a greater effect, suggesting higher toxicity. Another study by Katsouyanni and colleagues looked at several groups of such city characteristics. ${ }^{8}$ They reported a higher effect of $\mathrm{PM}_{10}$ on mortality in cities with a lower ratio of $\mathrm{PM}_{10}$ to nitrogen dioxide $\left(\mathrm{NO}_{2}\right)$ in the pollution mix, higher mean daily temperature, lower mean relative humidity, lower standard mortality rates, and higher proportion of susceptibles (age 65 years or older).

We found densely populated cities to have a greater effect of $\mathrm{PM}_{10}$ on daily mortality. We hypothesised that there were two reasons why denser cities had more daily deaths due to air pollution exposure. First, there may be a greater toxicity of the source particles, or, second, the population in denser cities may be more susceptible. Denser populated cities, in general, tend to be more urban, and thus a larger percentage of the primary $\mathrm{PM}_{10}$ is from traffic sources. The finding we obtained for percentage of primary $\mathrm{PM}_{10}$ from traffic corroborated this hypothesis. These results corresponded well 


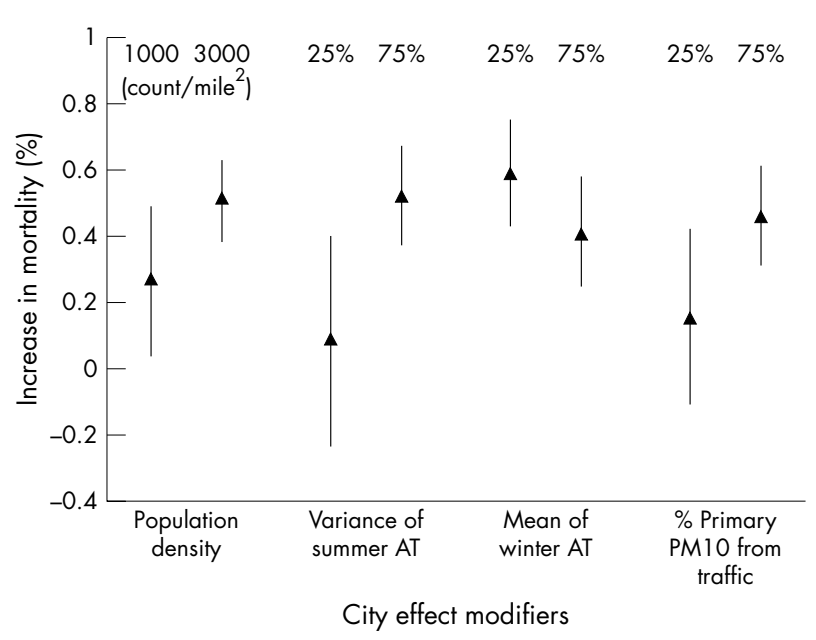

Figure 1 Effect modification by city characteristics in the 20 cities in the United States, between 1989 and 2000. AT, apparent temperature; $\mathrm{PM}_{10}$, particulate matter of aero-diameter $\leqslant 10 \mu \mathrm{m}$. The two estimates and their $95 \% \mathrm{Cl}$ for each of the modifying factors represent the percentage increase in mortality for any $10 \mu \mathrm{g} / \mathrm{m}^{3}$ of $\mathrm{PM}_{10}$, for the 25 th centile, and 75th centile of the modifier distribution across the 20 cities. For population density, the percentage increase in mortality per $10 \mu \mathrm{g} /$ $\mathrm{m}^{3}$ of $\mathrm{PM}_{10}$ is presented for 1000 count $/ \mathrm{mile}^{2}$, and 3000 count $/ \mathrm{mile}^{2}$.

with results of Laden and colleagues, ${ }^{60}$ who found greater toxicity from traffic particles in a source apportionment mortality study. This is also broadly consistent with the results of Katsouyanni and colleagues. ${ }^{8}$ The lower ratio of $\mathrm{PM}_{10}$ to $\mathrm{NO}_{2}$, which modified the particle effect in that study, could be interpreted as indicating a city with a larger proportion of particles from traffic, which generates most of the $\mathrm{NO}_{2}$ in urban areas. It may also explain the lower effect size estimates reported from Eastern Europe, ${ }^{48}$ where coal combustion accounts for a much larger proportion of the particles than in Western Europe. The difference in the toxicity of particles from different sources could be a result of the differences in specific components of particles. ${ }^{26}$

The second hypothesis, that such a difference in effects could be due to a more susceptible population in denser cities, was only partly supported when examining the age distribution in our study, as well as when examining the potential for modifying the $\mathrm{PM}_{10}$ effects of age standardised mortality rates, and the proportion of those greater than 65 , 75 , or 85 years old, in each city. Katsouyanni and colleagues had seen the greater effect of $\mathrm{PM}_{10}$ in cities with lower age standardised mortality rates, ${ }^{8}$ and with higher proportion of older ages (greater than 65 years). No modifying effect of age standardised mortality rates was seen in our study. However, the study findings suggested that a greater impact of $\mathrm{PM}_{10}$ concentrations was present in cities with a larger proportion of those older that 65 or 75 years.

A new observation of ours was a higher effect of $\mathrm{PM}_{10}$ in cities with greater summer temperature variability. High variability in temperature may be related to exposure differences, as more days with open windows may occur in the summer time in cities with such variability, compared to cities that are consistently hot in the summer, where continual air conditioning use is more common. Higher ventilation is associated with a steeper slope of the association between personal exposure to particles and ambient concentrations. ${ }^{61}$ The finding of a higher effect of $\mathrm{PM}_{10}$ in Mediterranean cities in the multicentre European study of air pollution (APHEA II) may reflect the same exposure phenomena, ${ }^{8}$ as air conditioning is rare in those cities, and high ventilation rates are the norm in the summer. Alternatively, this modification may result from some interaction between temperature exposure and exposure to air pollution. ${ }^{62}$ However, Samet and coworkers did not observe any interaction between temperature and air pollution in Philadelphia. ${ }^{63}$ Cooler winter temperatures are associated with increased mortality risk; ${ }^{4864} 65$ they also appeared to modify the effects of air pollution in our study.

We note that some city characteristics may vary over a 12 year period, and we were limited on this by data availability. However, population density, and apparent temperature may not, on average, vary by much in a 12 year period.

Most of the specific groups of diseases examined in this study are strongly influenced by other risk factors, such as individual social habits (smoking and drinking), and individual characteristics. In our study, we controlled for this by design, using a case-crossover sampling. In such study each case serves as its control on the event-free days. This

Table 4 Modification of "all-cause" daily mortality; $\mathrm{PM}_{10}$ association by city characteristics* across 20 cities in the United States, between 1989 and 2000

\begin{tabular}{|c|c|c|c|c|c|c|c|c|}
\hline \multirow[b]{2}{*}{ City characteristics } & \multicolumn{2}{|c|}{ Effect modifier coefficient† } & \multicolumn{3}{|c|}{$\%$ increase at the 25 th centile } & \multicolumn{3}{|c|}{$\%$ increase at the 75 th centile } \\
\hline & $\%$ & $95 \% \mathrm{Cl}$ & 1st quartile & $\%$ & $95 \% \mathrm{Cl}$ & 3rd quartile & $\%$ & $95 \% \mathrm{Cl}$ \\
\hline$\%$ Central air conditioning & -0.13 & -1.42 to 1.15 & 24.8 & 0.45 & 0.17 to 0.72 & 56.1 & 0.41 & 0.11 to 0.70 \\
\hline Population density (count/mile ${ }^{2}$ ) & $0.12 \S$ & 0.04 to 0.20 & 1000 & 0.27 & 0.04 to 0.49 & 3000 & 0.51 & 0.38 to 0.63 \\
\hline Age standardised mortality rate & -25.5 & -198.8 to 147.8 & 0.008 & 0.47 & 0.17 to 0.80 & 0.010 & 0.41 & 0.17 to 0.66 \\
\hline$\%>65$ years old & 0.05 & -0.01 to 0.11 & 10.3 & 0.34 & 0.11 to 0.58 & 14.3 & 0.53 & 0.33 to 0.74 \\
\hline$\%>75$ years old & 0.08 & -0.04 to 0.20 & 5.1 & 0.36 & 0.12 to 0.59 & 7.3 & 0.54 & 0.32 to 0.76 \\
\hline$\%>85$ years old & 0.22 & -0.28 to 0.71 & 1.3 & 0.37 & 0.13 to 0.62 & 1.8 & 0.49 & 0.27 to 0.72 \\
\hline \multicolumn{9}{|l|}{ Daily minimum summer $\mathrm{AT}\left({ }^{\circ} \mathrm{C}\right)$} \\
\hline Mean & -0.01 & -0.09 to 0.06 & 22.3 & 0.45 & 0.16 to 0.74 & 24.7 & 0.41 & 0.09 to 0.73 \\
\hline Variance & $0.41 \S$ & 0.14 to 0.67 & 3.6 & 0.09 & -0.23 to 0.40 & 4.7 & 0.52 & 0.37 to 0.67 \\
\hline \multicolumn{9}{|l|}{ Daily maximum winter $\mathrm{AT}\left({ }^{\circ} \mathrm{C}\right)$} \\
\hline Mean & $-0.08 \S$ & -0.14 to -0.03 & -2.9 & 0.59 & 0.43 to 0.75 & -0.8 & 0.41 & 0.25 to 0.58 \\
\hline Variance & 0.10 & -0.16 to 0.36 & 4.4 & 0.40 & 0.17 to 0.62 & 5.5 & 0.51 & 0.25 to 0.76 \\
\hline$\%$ of primary $\mathrm{PM}_{10}$ from traffic & $0.16 \S$ & 0.06 to 0.26 & 2.4 & 0.15 & -0.11 to 0.42 & 4.4 & 0.46 & 0.31 to 0.61 \\
\hline
\end{tabular}

$\mathrm{PM}_{10}$, particulate matter of aero-diameter equal or less than $10 \mu \mathrm{m}$.

*Effect modification by city characteristics was examined for the three day cumulative effect for all-cause mortality.

†The estimates represent the coefficient of the interaction term for the tested modifier on the mortality-PM $\mathrm{P}_{10}$ association. The estimates for the city effect modifiers are presented as percentage increase in mortality per $10 \mu \mathrm{g} / \mathrm{m}^{3}$ increase in $\mathrm{PM}_{10}$, per every unit increase in the modifier as shown in the table. The estimate for population density is presented as percent increase in mortality per each increment of $10 \mu \mathrm{g} / \mathrm{m}^{3}$ of $\mathrm{PM}_{10}$, per 1000 count $/ \mathrm{mile}{ }^{2}$.

†The estimates are presented as percentage increase in mortality per $10 \mu \mathrm{g} / \mathrm{m}^{3}$ of $\mathrm{PM}_{10}$, for the 25 th centile and 75 th centile of the distribution of city effect modifiers. For population density, the estimates are presented as percentage increase in mortality per of $10 \mu \mathrm{g} / \mathrm{m}^{3}$ of PM 10 , for 1000 count/mile ${ }^{2}$ and 3000 count/mile ${ }^{2}$.

$\S$ Significant at $\alpha=0.05$. 


\section{Main messages}

- Particulate matter has been associated with short term increases in morbidity and mortality.

- The study found increased all-cause, respiratory, and heart disease mortality in association with particulate matter of aero-diameter $\leqslant 10 \mu \mathrm{m}\left(\mathrm{PM}_{10}\right)$, with effects being persistent over several days. Matching control days on temperature did not change this association.

- Several city characteristics modified the effects of $\mathrm{PM}_{10}$ on daily mortality, notably the percentage of particles from traffic.

way we matched perfectly on potential confounders that change slowly over time..$^{4-43}$

This study did not address other air pollutants, in multiple pollutant scenarios. We made this choice for several reasons. First, the NMMAPS study, using more cities, and hence with more power, showed that gaseous pollutants were not confounders of the effects of $\mathrm{PM}_{10} .{ }^{5}$ The $\mathrm{PM}_{10}$ effects were not significantly changed by the presence of other copollutants in the models, in two or multiple pollutant models, nor were any of the other pollutants significant predictors of daily deaths, even in single pollutant models. Second, a very recent study by Schwartz controlled for confounding by co-pollutants in a case-crossover analysis by choosing control days that were matched on each gaseous pollutant in turn, and again, found no significant change in the estimates of $\mathrm{PM}_{10}$-mortality association, suggesting a causal relation between $\mathrm{PM}_{10}$ and daily mortality. ${ }^{66}$ Finally, two studies by Sarnat and colleagues have shown that ambient concentrations of gaseous pollutants may be surrogates for exposure to particulate matter, and indeed have stronger associations with exposure to particles than with exposure to the respective gases..$^{6167}$ Under such circumstances, controlling for an ambient gaseous pollutant, risks putting two surrogates for the same thing in a regression model, which is inappropriate.

In summary, the study showed important associations between all-cause and cause specific mortality and $\mathrm{PM}_{10}$, in a multi-city study in the United States including the most recent 12 year period of available data. The findings of our study corroborated those of earlier studies reported in Europe and the United States, ${ }^{4-6} 89{ }^{13}$ including findings of immediate effects for MI, and effects spread over two to three days for most other causes. The observed persistent effect of $\mathrm{PM}_{10}$ does support the findings of several other studies. ${ }^{13}{ }^{46}$ It also confirmed previous findings that certain characteristics which are particular to a location, either geographically or demographically, can affect the mortality-air pollution association. ${ }^{85} 36$ In particular, we found evidence that traffic particles are more toxic. On the other hand, we did not confirm the European findings of effect modification by age standardised mortality rates. In any event, such differing effects are important to consider in policy matters of regulating air pollution standards.

\section{Authors' affiliations}

A Zeka, A Zanobetti, J Schwartz, Exposure, Epidemiology, and Risk Program, Department of Environmental Health, Harvard School of Public Health, Boston, MA, USA

Funding: supported by the Harvard Environmental Protection Agency (EPA) PM Center, Grant R827353, and National Institute for Environmental Health Science (NIEHS) ESO002

Competing interests: none declared

\section{Policy implications}

- Reducing levels of particulate matter may contribute to reducing mortality associated with it.

- Attention must be paid to traffic related air pollution, as suggestive of higher toxicity.

\section{REFERENCES}

1 Schwartz J, Dockery DW. Increased mortality in Philadelphia associated with daily air pollution concentrations. Am Rev Respir Dis 1992;145:600-04.

2 Schwartz J. Air pollution and daily mortality in Birmingham, Alabama. Am J Epidemiol 1993;137:1136-47.

3 Pope CA 3rd, Bates DV, Raizenne ME. ealth effects of particulate air pollution: time for reassessment? Environ Health Perspect 1995;103:472-80.

4 Katsouyanni K, Touloumi G, Spix C, et al. Short-term effects of ambient sulphur dioxide and particulate matter on mortality in 12 European cities: results from time series data from the APHEA project. Air Pollution and Health: a European Approach. BMJ 1997;314:1658-63.

5 Dominici F, McDermott A, Daniels M, et al. Mortality among residents of 90 cities. In: Revised analyses of time-series studies of air pollution and health. Special report, Health Effects Institute. Montpelier, VT: Capital City Press, 2003.

6 Schwartz J, Dockery DW, Neas LM. Is daily mortality associated specifically with fine particles? J Air Waste Manag Assoc 1996;46:927-39.

7 Wichmann HE, Spix C, Tuch T, et al. Daily mortality and fine and ultrafine particles in Erfurt, Germany. Part I: role of particle number and particle mass. Res Rep Health Eff Inst 2000;98:5-86.

8 Katsouyanni K, Touloumi G, Samoli E, et al. Confounding and effect modification in the short term effects of ambient particles on total mortality: results from 29 European cities within the APHEA2 project. Epidemiology 2001; 12:521-31.

9 Schwartz J. What are people dying of on high air pollution days? Environ Res 1994;64:26-35.

10 Zmirou D, Schwartz J, Saez M, et al. Time-series analysis of air pollution and cause-specific mortality. Epidemiology 1998;9:495-503.

11 Dominici F, McDermott A, Zeger SL, et al. National maps of the effects of particulate matter on mortality: exploring geographical variation. Environ Health Perspect 2003;111:39-44.

12 Omori T, Fujimoto G, Yoshimura I, et al. Effects of particulate matter on daily mortality in 13 Japanese cities. J Epidemiol 2003;13:314-22.

13 Braga AL, Zanobetti A, Schwartz J. The lag structure between particulate air pollution and respiratory and cardiovascular deaths in 10 US cities. J Occup Environ Med 2001;43:927-33.

14 Hong YC, Lee JT, Kim H, et al. Effects of air pollutants on acute stroke mortality. Environ Health Perspect 2002;1 10:187-91.

15 Hong YC, Lee JT, Kim H, et al. Air pollution: a new risk factor in ischemic stroke mortality. Stroke 2002;33:2165-9.

16 Kan H, Jia J, Chen B. Acute stroke mortality and air pollution: new evidence from Shanghai, China. J Occup Health 2003;45:321-3.

17 Tsai SS, Goggins WB, Chiu HF, et al. Evidence for an association between air pollution and daily stroke admissions in Kaohsiung, Taiwan. Stroke 2003;34:2612-16.

18 Peters A, Doring A, Wichmann HE, et al. Increased plasma viscosity during an air pollution episode: a link to mortality? Lancet 1997;349:1582-7.

19 Danesh J, Collins R, Appleby P, et al. Association of fibrinogen, C-reactive protein, albumin, or leukocyte count with coronary heart disease: metaanalyses of prospective studies. JAMA 1998;279:1477-82.

20 Pekkanen J, Brunner EJ, Anderson HR, et al. Daily concentrations of air pollution and plasma fibrinogen in London. Occup Environ Med 2000;57:818-22.

21 Fujii T, Hayashi S, Hogg JC, et al. Particulate matter induces cytokine expression in human bronchial epithelial cells. Am J Respir Cell Mol Biol 2001;25:265-71.

22 Peters A, Frohlich M, Doring A, et al. Particulate air pollution is associated with an acute phase response in men; results from the MONICA-Augsburg Study. Eur Heart J 2001;22:1198-204.

23 Utell MJ, Frampton MW, Zareba W, et al. Cardiovascular effects associated with air pollution: potential mechanisms and methods of testing. Inhal Toxicol 2002;14:1231-47.

24 Ishii H, Fujii T, Hogg JC, et al. Contribution of IL-1 beta and TNF-alpha to the initiation of the peripheral lung response to atmospheric particulates (PM10). Am J Physiol Lung Cell Mol Physiol 2004;287:L176-83.

25 Ghio AJ, Kim C, Devlin RB. Concentrated ambient air particles induce mild pulmonary inflammation in healthy human volunteers. Am J Respir Crit Care Med 2000;162:981-8.

26 Ghio AJ, Devlin RB. Inflammatory lung injury after bronchial instillation of air pollution particles. Am J Respir Crit Care Med 2001;164:704-8.

27 van Eeden SF, Tan WC, Suwa T, et al. Cytokines involved in the systemic inflammatory response induced by exposure to particulate matter air pollutants (PM(10)). Am J Respir Crit Care Med 2001;164:826-30.

28 Suwa T, Hogg JC, Quinlan KB, et al. Particulate air pollution induces progression of atherosclerosis. J Am Coll Cardiol 2002;39:935-42. 
29 Brook RD, Brook JR, Urch B, et al. Inhalation of fine particulate air pollution and ozone causes acute arterial vasoconstriction in healthy adults. Circulation 2002;105:1534-6.

30 Wellenius GA, Coull BA, Godleski JJ, et al. Inhalation of concentrated ambient air particles exacerbates myocardial ischemia in conscious dogs. Environ Health Perspect 2003;111:402-8.

31 Gurgueira S, Lawrence J, Coull B, et al. Rapid increases in the steady-state concentration of reactive oxygen species in the lungs and heart after particulate air pollution inhalation. Environ Health Perspect 2002;1 10:749-55.

32 Schwartz J. Air pollution and blood markers of cardiovascular risk. Environ Health Perspect 2001;109(suppl 3):405-9.

33 Brook RD, Brook JR, Rajagopalan S. Air pollution: the "heart" of the problem. Curr Hypertens Rep 2003;5:32-9.

34 Pope Cr, Hansen M, Long R, et al. Ambient particulate air pollution, heart rate variability, and blood markers of inflammation in a panel of elderly subjects. Environ Health Perspect 2004;1 12:339-45.

35 Schwartz J. Assessing confounding, effect modification, and thresholds in the association between ambient particles and daily deaths. Environ Health Perspect 2000;108:563-8.

36 Janssen NA, Schwartz J, Zanobetti A, et al. Air conditioning and sourcespecific particles as modifiers of the effect of $P M(10)$ on hospital admissions for heart and lung disease. Environ Health Perspect 2002;1 10:43-9.

37 Nehls G, Akland G. Procedures for handling aerometric data. J Air Pollution Control Assoc 1973;23:180-4.

38 Chow JC, Engelbrecht JP, Freeman NC, et al. Chapter one: exposure measurements. Chemosphere 2002;49:873-901.

39 Sarnat JA, Demokritou P, Koutrakis P. Measurement of fine, coarse and ultrafine particles. Ann Ist Super Sanita 2003;39:351-5.

40 Ozkaynak H, Schatz AD, Thurston GD. Relationships between aerosol extinction coefficients derived from airport visual range observations and alternative measures of airborne particle mass. Journal of the Air Pollution Control Association 1985;35:1176-85.

41 Maclure M. The case-crossover design: a method for studying transient effects on the risk of acute events. Am J Epidemiol 1991;133:144-53.

42 Bateson T, Schwartz J. Control for seasonal variation and time trend in casecrossover studies of acute effects of environmental exposures. Epidemiology 1999;54:596-605.

43 Bateson TF, Schwartz J. Selection bias and confounding in case-crossover analyses of environmental time-series data. Epidemiology 2001;12:654-61.

44 Lumley T, Levy D. Bias in the case-crossover design: implications for studies of air pollution. Envirometrics 2000;11:689-704.

45 Schwartz J, Zanobetti A, Bateson T. Morbidity and mortality among elderly residents in cities with daily PM measurements. In: Revised analyses of timeseries studies of air pollution and health. Special report, Health Effects Institute. Montpelier, VT: Capital City Press, 2003.

46 Schwartz J. The distributed lag between air pollution and daily deaths. Epidemiology 2000;11:320-6.

47 Braga AL, Zanobetti A, Schwartz J. The effect of weather on respiratory and cardiovascular deaths in 12 U.S. cities. Environ Health Perspect 2002;110:859-63.

48 Curriero FC, Heiner KS, Samet JM, et al. Temperature and mortality in 11 cities of the eastern United States. Am J Epidemiol 2002;155:80-7.
49 Steadman RG. The assessment of sultriness. Part II: Effects of wind, extra radiation and barometric pressure on apparent temperature. Journal of Applied Meteorology 1979;18:874-85.

50 Kalkstein LS, Valimont KM. An evaluation of summer discomfort in the United States using a relative climatological index. Bulletin American Meteorological Society 1986;67:842-8.

51 Schwartz J. The effects of particulate air pollution on daily deaths: a multi-city case crossover analysis. Occup Environ Med 2004;61:956-61.

52 Berkey CS, Hoaglin DC, Mosteller F, et al. A random-effects regression model for meta-analysis. Stat Med 1995; 14:395-411.

53 Fischer $\mathbf{P}$, Hoek G, Brunekreef B, et al. Air pollution and mortality in the Netherlands: are the elderly more at risk? Eur Respir J Suppl 2003;40:34-8.

54 Zelikoff JT, Chen LC, Cohen MD, et al. Effects of inhaled ambient particulate matter on pulmonary antimicrobial immune defense. Inhal Toxicol 2003;15:131-50.

55 Mittleman MA, Mintzer D, Maclure M, et al. Triggering of myocardial infarction by cocaine. Circulation 1999;99:2737-41.

56 Mittleman MA, Lewis RA, Maclure $M$, et al. Triggering myocardial infarction by marijuana. Circulation $2001 ; 103: 2805-9$.

57 Peters A, Dockery DW, Muller JE, et al. Increased particulate air pollution and the triggering of myocardial infarction. Circulation 2001;103:2810-15.

58 Hoek G, Brunekreef B, Fischer $P$, et al. The association between air pollution and heart failure, arrhythmia, embolism, thrombosis, and other cardiovascular causes of death in a time-series study. Epidemiology 2001;12:355-7.

59 Goldberg MS, Burnett RT, Valois MF, et al. Associations between ambient air pollution and daily mortality among persons with congestive heart failure. Environ Res 2003;91:8-20.

60 Laden F, Neas LM, Dockery DW, et al. Association of fine particulate matter from different sources with daily mortality in six U.S. cities. Environ Health Perspect 2000;108:941-7.

61 Sarnat JA, Koutrakis P, Suh HH. Assessing the relationship between personal particulate and gaseous exposures of senior citizens living in Baltimore, MD. J Air Waste Manag Assoc 2000;50:1 184-98.

62 Katsouyanni K, Pantazopoulou A, Touloumi G, et al. Evidence for interaction between air pollution and high temperature in the causation of excess mortality. Arch Environ Health 1993;48:235-42.

63 Samet J, Zeger S, Kelsall J, et al. Does weather confound or modify the association of particulate air pollution with mortality? An analysis of the Philadelphia data, 1973-1980. Environ Res 1998;77:9-19.

64 Group TE. Cold exposure and winter mortality from ischaemic heart disease cerebrovascular disease, respiratory disease, and all causes in warm and cold regions of Europe. Lancet 1997;10:1341-6.

65 Braga AL, Zanobetti A, Schwartz J. The time course of weather-related deaths. Epidemiology 2001;12:662-7.

66 Schwartz J. Is the association of airborne particles with daily deaths confounded by gaseous air pollutants? An approach to control by matching Environ Health Perspect 2004;1 12:557-61.

67 Sarnat JA, Brown KW, Schwartz J, et al. Ambient gas concentrations and personal particulate matter exposures: implications for studying the health effects of particles. Epidemiology 2005;16:385-95. 